\title{
TIERRA, IDENTIDAD Y SENTIDO DE PERTENENCIA EN EL NOVO CINEMA GALEGO
}

\author{
Terra, identidade e sentido de pertença no novo cinema galego
}

Land, identity, and sense of belonging in the Novo Cinema Galego

\author{
Silvia Roca-Baamonde \\ Doutora em Comunicação e Informação Contemporânea pela \\ Universidade de Santiago de Compostela \\ silvia.roca@usc.es
}

Marta Pérez-Pereiro Professora do Departamento de Ciências da Comunicação da Universidade de Santiago de Compostela marta.perez.pereiro@usc.es

\begin{abstract}
Resumo
O cinema retratou a natureza e suas mais variadas expressões desde o seu início, mas apenas nas últimas décadas uma perspectiva ecológica foi adotada para analisar aqueles filmes em que se encena a relação do ser humano com o ambiente natural. Embora o termo Ecocine tenha sido desenvolvido teoricamente por Roger C. Anderson em 1975, foi no século XXI quando houve uma expansão do campo de estudo (MURRAY \& HEUMANN, 2009; RUST, MONANI \& CUBITTY, 2012; PICK \& NARRAWAY, 2013) e o ecocriticism tem sido aplicado às cinematografias nacionais (BRERETON, 2004; KÄAP ̈̈, 2015) ou a autores ou filmes singulares. Nessa perspectiva, analisaremos os filmes $O$ que arde (Oliver Laxe, 2019), Trote (Xacio Baño, 2018) e Trinta Lumes (Diana Toucedo, 2017), três obras que, com o selo Novo Cinema Galego, apresentam o desaparecimento da vida rural na Galiza contemporânea e a consequente mudança na relação das pessoas com o meio natural.
\end{abstract}

Palavras-chave: Novo Cinema Galego. Ecocinema. Identidade.

\begin{abstract}
Cinema has portrayed nature and its multiple expressions since its early manifestations, but only in the last decades, film studies have adopted an ecological perspective to analyse how films put in scene the relation of humanity with nature. Although the term Ecocinema has theoretically developed by Roger C. Anderson in 1975, it was not until the beginning of the XXI century when there was extension of the field of study (MURRAY \& HEUMANN, 2009; RUST, MONANI \& CUBITTY, 2012; PICK \& NARRAWAY, 2013). Ecocriticism has applied to national cinemas (BRERETON, 2004; KÄAPÄ, 2015) or to singular films or authors. From the ecocinema perspective, we will analyse the films $O$ que arde (Oliver Laxe, 2019), Trote (Xacio Baño, 2018) and Trinta Lumes (Diana Toucedo, 2017). These three films, part of the production of the Novo Cinema Galego - New Galician Cinema - show the disappearance of rural life in contemporary Galicia and the transformation in the relation of people with the natural environment.
\end{abstract}


Key words: Novo Cinema Galego. Ecocinema. Identity.

\section{Resumen}

El cine ha retratado la naturaleza y sus más variadas expresiones desde sus inicios, pero sólo en las últimas décadas se ha adoptado una perspectiva ecológica para analizar aquellos filmes en los que se pone en escena la relación del ser humano con el medio natural. Aunque el término Ecocine fue desarrollado teóricamente por Roger C. Anderson en 1975, ha sido en el siglo XXI cuando se ha producido una ampliación del campo de estudio (MURRAY \& HEUMANN, 2009; RUST, MONANI \& CUBITTY, 2012; PICK \& NARRAWAY, 2013) y la ecocrítica se ha aplicado a cinematografías nacionales (BRERETON, 2004; KÄAPÄ, 2015) o a autores o filmes singulares. Desde esta perspectiva, analizaremos los filmes $O$ que arde (Oliver Laxe, 2019), Trote (Xacio Baño, 2018) y Trinta Lumes (Diana Toucedo, 2017) tres obras que, con el sello del Novo Cinema Galego, presentan la desaparición de la vida rural en la Galicia contemporánea y el consiguiente cambio de relación de las personas con el medio natural.

Palabras clave: Novo Cinema Galego. Ecocinema. Identidad.

\section{INTRODUCCIÓN}

El retrato de la naturaleza y la filmación del paisaje y de la tierra conforman una constante del cine hecho en Galicia desde sus primeras manifestaciones, y continúan siéndolo en un movimiento cinematográfico reciente, el Novo Cinema Galego, que congrega las propuestas más contemporáneas y vanguardistas que brotan en esta pequeña nación sin Estado de la periferia europea. Cine desde los márgenes y hacia los márgenes, la aparición de esta etiqueta en los círculos cinéfilos ${ }^{1}$ y su consolidación en el circuito internacional de festivales sirvieron para dar nombre a una nueva ola de cineastas que, a pesar de sus diferencias, comparten cuantiosos factores en común y confluyen en una clara apuesta por nuevas formas de ver, entender y hacer cine para y desde Galicia. La investigadora y docente Beli Martínez (2015, 2015 b), productora a su vez de muchos de los filmes de esta nueva corriente, apunta como señales de identidad compartidas del movimiento el uso de tecnologías digitales, —más accesibles que los equipos analógicos para cine-, la opción por la autoproducción, —en una tendencia que brota en la periferia de la industria y que opta por nuevas vías y mecanismos de distribución - , y el amateurismo y la cinefilia, una declarada pasión por el cine que se traduce en un diálogo constante entre los filmes y sus responsables, y en el surgimiento de una escena

\footnotetext{
${ }^{1}$ Se atribuye a los críticos y programadores de cine Martín Pawley, Xosé Manuel Sande y Xurxo González, todos de origen gallega, la ideación de esta etiqueta con el objeto hacer visible ante los responsables autonómicos de ayudas públicas para el fomento de la cinematografía la efervescencia creativa y el talento de esta nueva ola de creadoras y creadores (MARTÍNEZ, 2015b, p. 131).
} 
intelectual activa y fructífera alrededor de este cambio de paradigma. De ella da cuenta el portal "Novo Cinema Galego. Arquivo das novas prácticas cinematográficas da Galiza" [Nuevo Cine Gallego. Archivo de las nuevas prácticas cinematográficas de Galicia] (http://novocinemagalego.info/), un gran contenedor cultural de acceso libre que procura dar visibilidad a las nuevas fórmulas, las creaciones y las voces nacidas al amparo de esta etiqueta, y coincidentes en el "desarrollo de modelos de producción que difieren de los parámetros industriales", la "utilización de lenguajes revolucionarios que ponderan la experimentación” y "la existencia de un valor más allá del hecho puramente fílmico, que ayuda a desarrollar y a potenciar este tipo de cine Galicia" (novocinemagalego. info, s.f.).

El Novo Cinema Galego, en definitiva, se constituye como una nueva apuesta que desvela la capacidad de operar desde la "discontinuidad, la invisibilidad y la periferia" características de la pequeña producción cultural que es el cine de Galicia (PÉREZ PEREIRO, 2014 , p. 77) y conseguir una notoria presencia internacional y numerosos premios de la crítica y el circuito profesional. El premio FIPRESCI que el filme Todos vós sodes capitáns (Oliver Laxe, 2010) recibió en la Quinzaine des Réalisateurs del festival de Cannes inició una década de éxitos a la que contribuyeron otros títulos como $O$ quinto evanxeo de Gaspar Hauser (Alberto Gracia, 2013), premio de la crítica en el Festival de Rotterdam; Costa da Morte (Lois Patiño, 2013), premio al mejor director emergente del Festival de Locarno; Matria (Álvaro Gago, 2013), premio del jurado del Festival Internacional de Cine de Sundance; Mimosas (Oliver Laxe, 2016), gran premio en la Semaine de la Critique de Cannes; Dhogs (Andrés Goteira, 2017), premio de la crítica en el BIFF Bruselas; Longa Noite (Eloy Enciso, 2019), premio Boccalino D'Oro del Festival de Locarno; o la reciente $O$ que arde (Oliver Laxe, 2019), premio del jurado en la sección oficial "Un Certain Regard" de nuevo en el festival francés 2 . Este afluente de filmes, apenas una muestra de una corriente mucho más nutrida de películas que transitan por numerosos festivales y encuentros, comportan, como hemos señalado en textos anteriores (PÉREZ PEREIRO, 2014) los elementos que Mette Hjort (2007) considera imprescindibles para garantizar la visibilidad y viabilidad internacional de una cinematografía y acreditar su legitimidad más allá de sus fronteras territoriales, a saber:

La garantía de la diversidad expresiva, un buen porcentaje en la billetera nacional, la obtención de premios en el circuito internacional, cierta

\footnotetext{
${ }^{2}$ La tendencia parece continuar en la presente década con nuevos reconocimientos, como el Premio Málaga Talent que Oliver Laxe recogió en la 24 edición del Festival de Málaga, o los recibidos por las películas Nación (Margarita Ledo Andión, 2020), Premio del Festival Europeo de Sevilla a la mejor dirección en España; o Sycorax (Lois Patiño, 2021), seleccionada y estrenada en la Quinzaine des Realisateurs de Cannes del presente año.
} 
distribución internacional, la financiación de sectores privados y públicos en los ámbitos nacional y supranacional y una plataforma para que los profesionales del sector tengan oportunidades en el mercado nacional (PÉREZ PEREIRO, 2014, p. 80).

Al tiempo, irrumpen con rotundidad en el debate sobre las estrategias de pervivencia y éxito de un pequeño cine, el gallego, a la procura de una identidad propia.

Como parte de este entramado, este artículo explora los filmes $O$ que arde (Oliver Laxe, 2019), Trote (Xacio Baño, 2018) y Trinta Lumes (Diana Toucedo, 2017), tres obras que, con el sello del Novo Cinema Galego, presentan la desaparición de la vida rural en la Galicia contemporánea y el consiguiente cambio de relación de las personas con el medio natural. La cuestión nacional, problematizada en relación con la ecología por Käapä (2015) se vincula con la presentación de la naturaleza como un símbolo, en peligro de extinción, de la identidad gallega. En este sentido, observamos si existe una correlación directa entre la nación y la naturaleza que podría rastrearse en la representación del medio ambiente en películas gallegas anteriores. En unas y otras, el cuidado y respeto por el medio ambiente aparece de manera recurrente, si bien no explícita, entre los temas centrales.

\section{EL NOVO CINEMA GALEGO BAJO EL PRISMA DEL ECOCINEMA}

Más allá de las concurrencias procesales ya comentadas ${ }^{3}$, los filmes del Novo Cinema Galego comparten también ciertas características formales y estilísticas que rompen con las propuestas comerciales que el sector cinematográfico gallego venía articulando hasta entonces y que pasaban, en la mayor de los casos, por aportaciones desposeídas de los rasgos diferenciales de la cultura de Galicia para hacerlas más próximas a lo que se ansiaba como público potencial: el espectador estatal. Filmes en español ${ }^{4}$, la mayor parte de las veces rodados en el entorno urbano con una intencionada ambigüedad espacial que permitía situar la acción en cualquier otro lugar y esquemas narrativos clásicos.

Frente a esta vía, los filmes del Novo Cinema Galego, evidentes herederos de los movimientos cinematográficos y nuevos cines surgidos en la escena internacional en los años 60 y 70 y también del circuito de cine no profesional y amador que se desarrolló en Galicia en la misma época ${ }^{5}$, proponen fórmulas bien distintas que exploran la riqueza de la diferencia y muestran su valor en el diálogo cultural.

\footnotetext{
${ }^{3}$ Y también detalladas en Redondo Neira, Fernando \& González Rodríguez, Xurxo (2015).

4 Cfr. Roca Baamonde, Silvia, Pérez Pereiro, Marta \& Rodríguez Vázquez, Ana Isabel (2016).

5 Analizado en profundidad por Xan Gómez Viñas en la tesis Do amateur ao militante implicacións políticas e estéticas do cinema en formato non profesional na Galiza dos anos 70 (2015).
} 
Filmar "la tierra, la gente y el paisaje; el vacío, la ausencia y el recuerdo; cuerpos, lugares y gestos, más que palabras y tramas" (CASTRO DE PAZ, 2019) se convierten en recursos clave en la búsqueda de nuevas modalidades expresivas que se encuadran, según José Luis Castro de Paz, en la línea de un cine internacional

[...] ya no contemplativo sino substractivo (FIANT, 2014) basado en una extrema economía estilística ("detención del tiempo", ficción minimalista, despojo de una narración esquiva e irresuelta, en la que se eliden los núcleos y se muestran breves y en apariencia azarosos y en principio intrascendentes fragmentos; elipsis y silencios; calma o movimiento de la cámara siempre excesivos en comparación con las convenciones clásicas o incluso modernas); ausencia de música extradiegética; limitación gestual y emocional del actor), convertida en constante $-\mathrm{y}$ potencialmente esquemática y tópica por reiteración- fórm[ul]la que no obstante poseen y comparten - además de otros muchos- algunos de los títulos más relevantes del cine mundial de las últimas dos décadas (CASTRO DE PAZ, 2019, p. 157; comillas y cursivas del autor).

Estilemas comunes de las piezas de este nuevo cine —a los que sumamos la pérdida de prejuicios hacia el gallego como lengua cinematográfica, la huella documental y la proliferación de personajes femeninos - que procuran y favorecen la participación activa de un espectador transnacional al que apelan a nivel cognitivo y afectivo (INGRAM, 2012). En esta llamada discursiva, en este reto brechtiano, la vuelta a la espacialidad rural y el alargamiento del tiempo del metraje juegan un rol capital que nos permite analizar el Novo Cinema Galego desde un entendimiento amplio del enfoque ecocinematográfico en tanto promotor de una evaluación crítica del papel de la humanidad en el mundo que nos rodea (RUST, MONANI \& CUBBIT, 2012) o como “el estudio de la producción y reproducción de la vida, la relación entre el cuerpo humano y el ecosistema, y el control y administración del cuerpo humano en los regímenes capitalista y socialista modernos" ( LU \& MI, 2009, p. 2). Pues si bien no anulan, cuando menos no totalmente, la perspectiva antropocéntrica, buena parte de los filmes de la corriente, y particularmente la tríada que traemos a análisis en este trabajo, nos invitan a repensar el papel de la humanidad en relación con la naturaleza y, en ocasiones, como veremos, diluyen las fronteras que concebimos entre el hombre y el medio, aproximándolos y haciéndolos parte de un mismo todo.

El retorno al retrato del paisaje gallego, desprovisto en estos filmes del complaciente aroma a lugar idílico con el que a menudo se presentaba en el cine comercial (ROCA 
BAAMONDE, 2021), y más próximo a la filmación de corte antropológico que marcaron los inicios del cine popular gallego (con la insigne Galicia-Finisterre de Carlos Velo, de 1936, como ejemplo más destacable), muestra, a tenor del evidente éxito de estos filmes que trascienden fronteras, la potencialidad del espacio rural gallego como marco susceptible de poner en escena tramas de interés y alcance internacional. Y así, sin obscurecer la especificidad local de un entorno marcadamente gallego, las propuestas consiguen trascender lo nacional y apelar a la preservación del sentimiento de pertenencia a la tierra de espectadores foráneos. El recurso a la naturaleza se convierte, así, en activo para la internalización del filme en una dinámica "transvergente" (KÄ̈̈Р̈̈, 2015) entre lo local y lo global.

En este dialógo, la diferenciada apuesta formal del Novo Cinema Galego ocupa un papel clave. Tal y como apunta Kääpä (2015), en el volumen Toward an Eco-cinema, Scott McDonald (2004) plantea una revisión del cine experimental y de sus capacidades para presentar al espectador un material fílmico, - $-\mathrm{y}$, añadimos nosotras, discursivo - complejo, que lo mueve a pensar diferente para usar después esa dinamización cognitiva con filmes politizados (KÄ̈̈PÄ, 2015, p. 6). A nuestro entender, es en este juego donde debemos analizar la pausa y la elongación del metraje que ya apuntamos como característica de todo el movimiento y, más en concreto, de los filmes que se tratan en este artículo. El efecto de choque que produce esa ralentización intencionada del tiempo y otras elecciones estéticas a las que aludimos en párrafos anteriores es fácilmente comprensible a la luz de estas palabras de James Benning, una de las miradas expertas en el retrato del paisaje del ámbito cinematográfico actual:

\begin{abstract}
Creo que quizás es la duración lo que ayuda a poner lo político de nuevo en escena. Primero, el acto de filmar de esa manera es algo político, sólo por el hecho de tomar una película variable y extenderla a un lugar donde la mayoría de la gente no vive, de manera que tal vez se sientan un poco incómodos con la duración. Pero también se ven obligados a abrirse a nuevas lecturas de lo que están viendo. Entonces, lo que al principio puede ser una experiencia totalmente estética, con suerte a través de la duración se descompone y hay indicios en la imagen que se vuelven políticos o sociales (Benning en PANSE, 2013, p. 65).
\end{abstract}

Por otro lado, la huella documental, marcada en toda esta cinematografía que transita, en buena parte de los casos, entre distintos grados de la no ficción, sirve de estímulo a nuestra reacción al cambio y consigue dotar ese debate, esa llamada hacia un posicionamiento activo, de mayor gravedad y profundidad. 
Pero junto a las propuestas narrativas y estilísticas, otros factores nos invitan a estudiar el Novo Cinema Galego a la luz de los Ecocinema Studies. Por las particularidades de su producción y su papel disruptor en una industria marcadamente capitalista caracterizada por la explotación de grandes recursos materiales, la "ideología constitutiva" (HAGEMAN, 2012) de esta cinematografía bien podría considerarse una apuesta ambientalista. Las estrategias y procedimientos que introducen - tecnologías accesibles, equipos humanos reducidos y circuitos de distribución alternativos - dan también pasos hacia la construcción de un nuevo paradigma, de modelos más sostenibles y respetuosos de hacer cine.

Marcadas las líneas de estudio que podríamos tener en consideración para observar este movimiento cinematográfico desde la perspectiva ecológica, pasamos ahora a analizar algunos de los detonadores de este cuestionamiento ecocrítico de los que dan cuenta tres de sus más recientes filmes: $O$ que arde (Oliver Laxe, 2019), Trote (Xacio Baño, 2017) y Trinta Lumes (Diana Toucedo, 2017).

\subsection{O que arde (Oliver Laxe, 2019)}

El rural vive un verdadero holocausto. No se puede hacer peor, no se puede tener tan poca visión... Son valores milenarios que se pierden. Aunque no hay que olvidar que, a pesar de su evidente decadencia, el mundo está bien hecho. Es decir, que el mundo tal como viene dado tiene sentido, que pasar por esta decadencia es necesario por algún motivo. Todos tenemos casas en la aldea que se están cayendo, con sus fincas a monte o a eucalipto. Hoy toca hacer del pasado presente y futuro, sin nostalgias ni romanticismo. Por una cuestión de puro pragmatismo. O supervivencia (Oliver Laxe, en CASANOVA, 2019).

Para su tercera película, la que le valdría la consagración internacional definitiva después de haber sido premiado en el Festival de Cannes con cada uno de sus tres largometrajes, el cineasta gallego Oliver Laxe decidió ambientar su relato en la aldea donde había nacido su madre. Vilela, una pequeña población ubicada en el corazón de la sierra de Os Ancares en la que el cineasta pasó buena parte de la infancia y con la que guarda una evidente relación afectiva (ABELENDA, 2019), sirve así de escenario a una trama que afronta sin reservas uno de los conflictos ambientales de la sociedad gallega: la sobreexplotación de los recursos forestales a través de la plantación de eucalipto, una especie arbórea australiana de la que Galicia es en la actualidad uno de los principales productores mundiales. La postura crítica respecto al cultivo del denominado "oro verde", considerado, por unos, fuente de cuantiosos ingresos y, por otros, causante del empobrecimiento del suelo y adyuvante de las sucesivas olas de incendios especialmente furibundas en los últimos años - que asolan el territorio del país, divide de forma 
lacerante a la población gallega. Laxe aprovecha ese conflictivo mapa anímico (y político) como marco en el que hacer aflorar la sensibilidad y la reacción de los espectadores ante la destrucción de la Galicia rural, y lo estimula a través de la personalización y humanización de la naturaleza en el filme. Así, en una de las escenas más memorables de la cinta, el dúo de protagonistas, - Amador, un pirómano que vuelve la aldea de la que es natural tras pasar varios años en la cárcel por haber provocado un incendio tiempo atrás en ese lugar, y su madre Benedicta, la personificación de la inocencia y la resiliencia-, mantienen un diálogo que ejemplifica esta personalización. Mientras ambos miran hacia diversos eucaliptos que rodean las fincas donde pastan sus vacas, él le dice:

Los eucaliptos salen a toda mecha buscando el cielo. Y sus raíces pueden tener kilómetros de largo. Si hurgas debajo de ellos, tienen un tejido, de la raíz, igualito que un saco viejo de patatas. Y cualquier árbol o planta que quiera salir, la ahogan. Son una plaga. Más malos que el demonio.

Ella, en una sentencia que constituye todo un alegato sobre la proximidad entre la naturaleza y la humanidad, apone: "Si hacen sufrir es porque sufren".

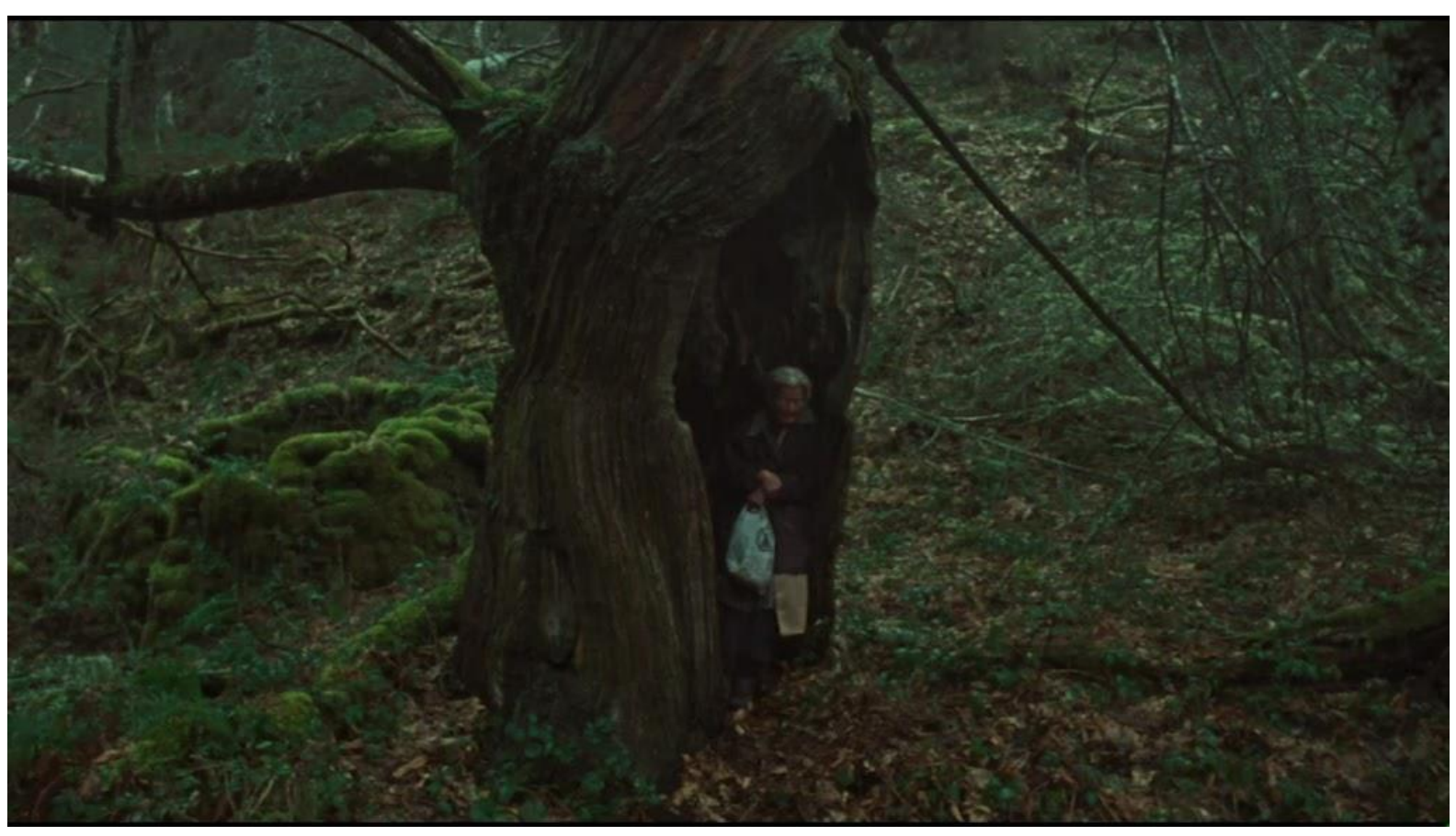

Figura 1. Fotograma de $O$ que arde (Oliver Laxe, 2019)

Este diluir de las distancias y las diferencias entre las personas y el medio se ve también favorecido por la relación física que los protagonistas mantienen con la naturaleza (vegetal o animal) que los rodea, con la que establecen un diálogo de total cercanía y organicidad. En una de las escenas que José Luis Castro de Paz (2020) destaca por su belleza plástica y por hacer 
gala de esta comunión a la que referimos, Benedicta, en medio de la lluvia, cruza con sorprendente ligereza fincas y riachuelos hasta llegar a guarecerse en la corteza vacía de un gran árbol que se convierte, con ese plano, en símbolo de la importancia de la preservación de la naturaleza para la conservación de la humanidad misma.

\subsection{Trote (Xacio Baño, 2018)}

La película parte de la premisa de tratar a las personas como animales. Los cuerpos como elementos finitos, que nos cierran. Nuestro mundo dura y abarca lo que podemos ver y sentir. No existe nada más que lo que está al alcance de los dedos. El tratamiento de las pieles animales y humanas, en detalle, tiene la finalidad de abstraerse de la figura completa, reducirnos a detalles y así igualarnos en la pirámide trófica. Cuanto más cerca se ve un organismo vivo, menos diferencias hay entre especies (Xacio Baño en YÁÑEZ, 2018).

Desde una estrategia diferente, aunque en evidente conexión con la enarbolada por Laxe, Xacio Baño, otra de las figuras destacadas del Novo Cinema Galego, articula en Trote un estudio cinematográfico sobre la necesidad de despojar al hombre de su civilización para liberarlo. En el que es su primer largometraje, el director compone un relato a medio camino entre dos violencias: una manifiesta, la presente en la Rapa das Bestas, una ancestral tradición consistente en la captura y marcaje de los caballos salvajes que se celebra en diferentes localidades del rural gallego y que es ampliamente explotada con fines turísticos; y una latente, la que se esconde en una familia de personajes heridos, encerrados, marcados por el dolor de haber perdido a la madre en un accidente de tráfico y que se muestran incapaces de vivir en compañía. 


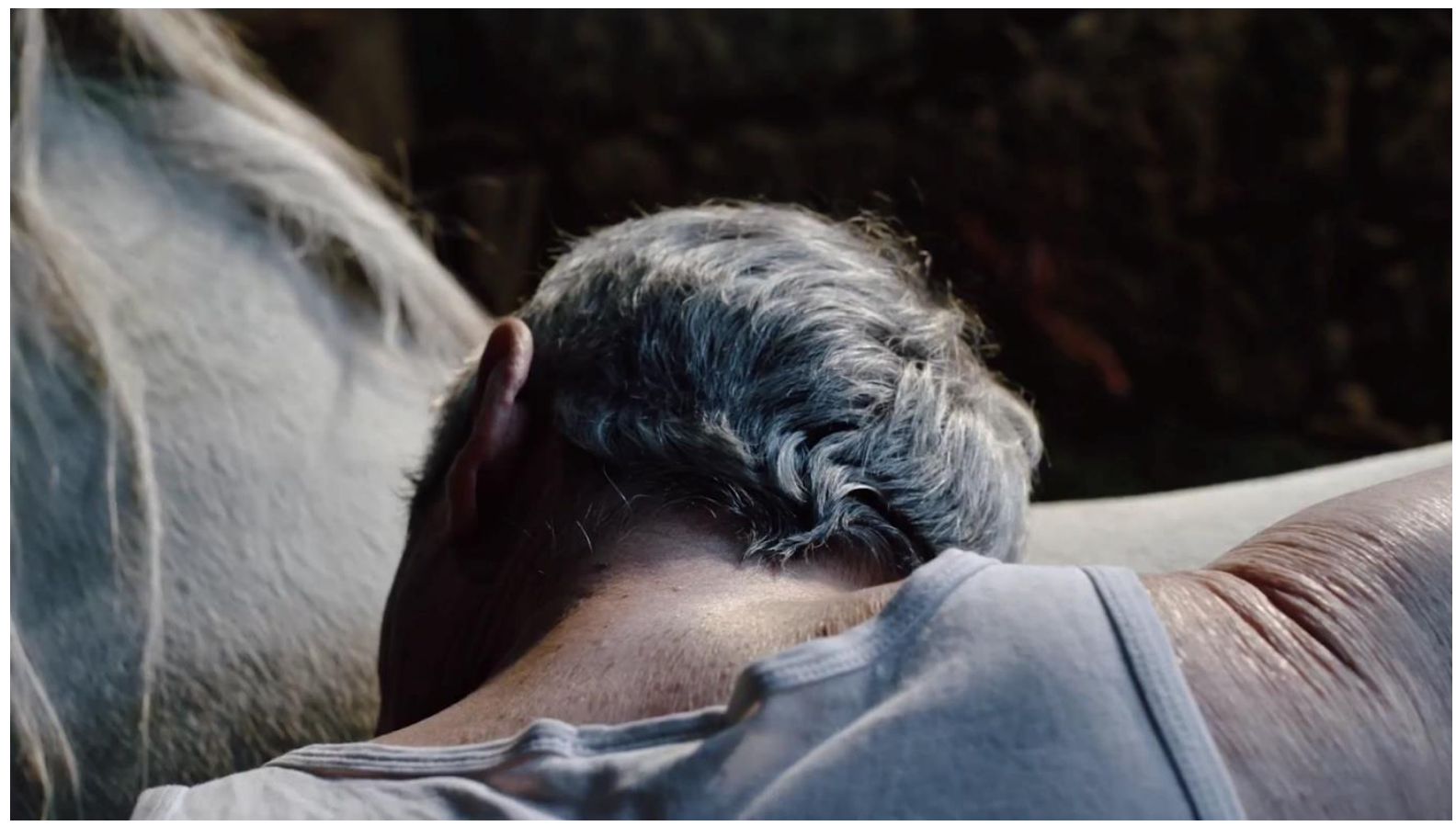

Figura 2. Fotograma de Trote (Xacio Baño, 2018)

La propuesta formal de Baño en la constitución de este filme de fuerte carga sensorial que busca despertar los instintos del espectador se apega a la fisicidad de los enfoques, a la conformación de una visualidad casi dérmica desde la que las diferencias entre el animal y el hombre se diluyen. Ambientada en el rural gallego, como el resto de los filmes que reunimos en este análisis, la película contrapone grandes planos generales que dan cuenta de la inmensidad natural que rodea la aldea, con encuadres cerrados y opresivos, con los que se retrata el espacio doméstico, lugares en que el habitante más notorio es el silencio y que se constituyen en cárcel de la felicidad humana. El peso aplastante de este confinamiento se traslada también a la actuación de los personajes que se consumen en su contención, en un hieratismo que los encadena y del que van saliendo de forma pausada a lo largo del filme. Es sólo cuando ceden a sus impulsos y abandonan su comportamiento civilizado cuando comienzan a respirar y, entonces, incluso sus movimientos se modifican y pasan de un modo de andar limitado y entumecido a una forma más próxima al cabalgar.

\subsection{Trinta Lumes (Diana Toucedo, 2017)}

La película de Diana Toucedo parte de varios de los tópicos narrativos de la cinematografía tradicional gallega, —el pensamiento mágico, la relación con la muerte y la presencia de las ánimas entre los vivos-, para componer un relato sobre el desvanecimiento y 
la despoblación del rural y deviene en un filme que María Soliña Barreiro Gonzlález (2019) destaca entre las producciones que conforman la "constelación cultural del duelo".

Duelo [colectivo] por un mundo que esmorece sin que fuésemos capaces de mantenerlo y sin que consiguiésemos imaginarnos sin él, muere el rural y con él sabemos - a pesar del absurdo disimulo - que muere también una identidad tejida y labrada en un territorio habitado y en el sostenerse en colectivo (BARREIRO, 2019, p. 21).

El título de la película hace referencia al número de casas aún habitadas en la pequeña población del Courel donde se sitúa la acción, una aldea en las montañas interiores de Galicia donde la densidad se estima por número de viviendas y no por el de habitantes (SÁNCHEZ, 2019; IGLESIAS, 2019). Treinta hogares resistentes que aún se calientan al calor de unas lumbres que se van achicando poco a poco y que están condenados a muerte.

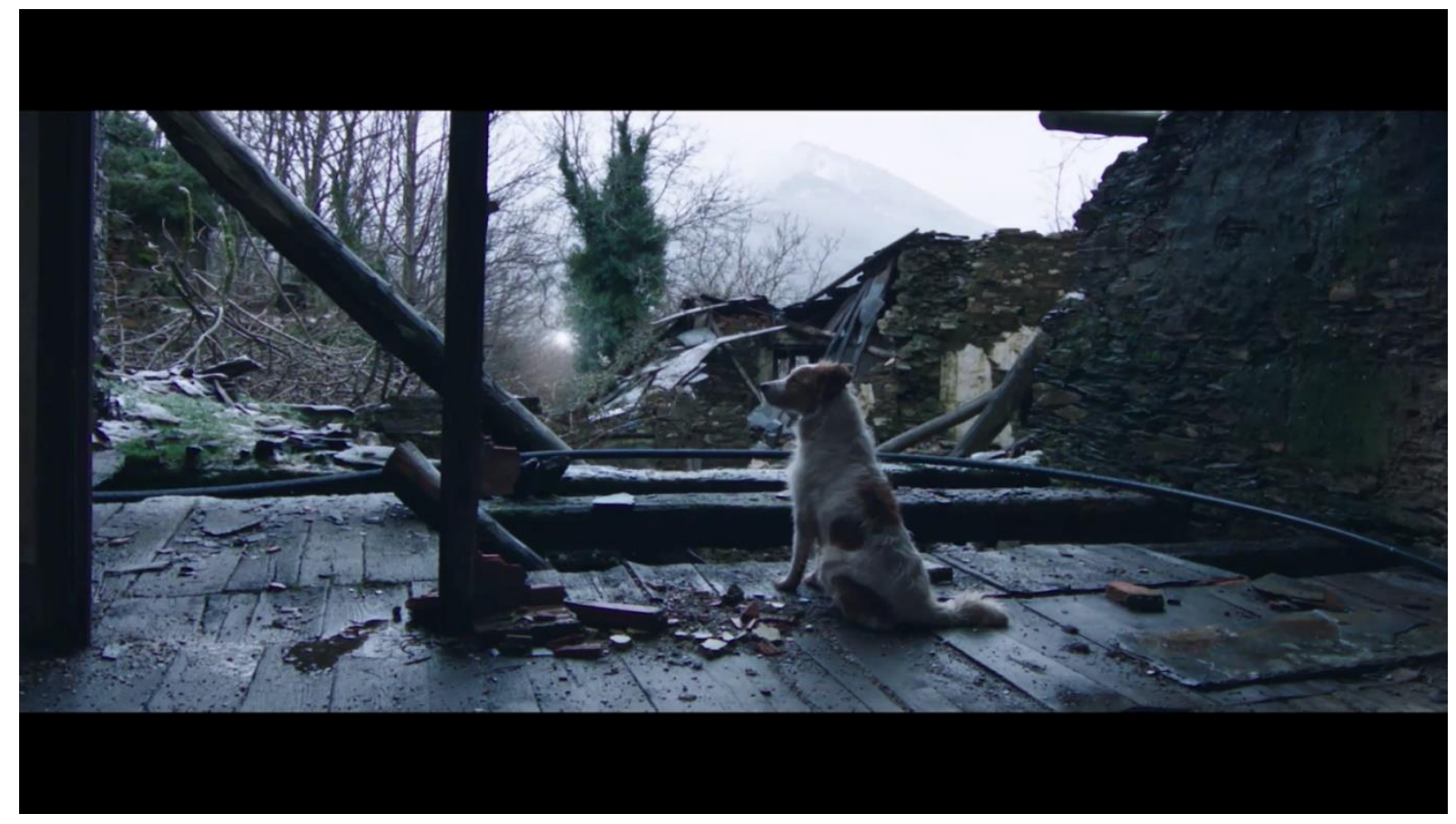

Figura 3. Fotograma de Trinta Lumes (Diana Toucedo, 2017)

De alguna manera, el filme participa de la perspectiva ambientalista en tanto que el motivo que parece estar tras esa muerte es el abandono de la naturaleza en favor de una pretendida modernidad que se nos antoja absurda y deslocalizada. Los contados niños de la aldea asisten a una escuela casi desierta en la que se forman mediante tecnologías punteras y en lengua inglesa para un futuro que saben y que les suponemos lejos de aquel lugar. Y, no obstante, asisten silenciosos a las prácticas (festivas, rituales, culinarias, agrarias, ganaderas) que eran habituales de ese entorno y que vemos preservadas en los también escasos pobladores de esa comunidad claramente envejecida. 
Si bien no podemos desconsiderar el enfoque antropocéntrico desde el que se teje el relato, el filme confronta al espectador con la imagen de la inevitable extinción de la humanidad mientras la naturaleza prosigue su curso. Y así, frente a los espacios vacíos y los silencios que los vivos dejan crecer entre sí, la naturaleza se muestra exuberante y sonora, insondable y resistente al paso del tiempo.

\section{CONSIDERACIONES}

Esta exploración inicial de diversos filmes del Novo Cinema Galego al amparo de los Ecocinema Studies revela las potencialidades que este enfoque ofrece para el análisis de las constantes narrativas, estilísticas y productivas de este particular movimiento cinematográfico y de las películas que en él se encuadran. Frente a las representaciones edulcoradas del paisaje gallego presente en numerosos filmes precedentes de esta cinematografía y en otras películas producidas en el entorno estatal, o a las aproximaciones de corte etnográfico que marcaron los inicios del cine popular gallego, estas películas se adentran en el retrato de la naturaleza como elemento discursivo y sitúan al espectador en una posición incómoda que mueve a la reflexión sobre su relación con el medio ambiente y la repercusión de este vínculo en su definición identitaria.

\section{REFERENCIAS}

ABELENDA, Ana (2019, 10 de octubre). Oliver Laxe: "Gustaríame ter mais fillos e menos películas, quero que a vida me supere". La Voz de Galicia. Recuperado de https://www.lavozdegalicia.es/noticia/fugas/2019/09/20/span-langgloliver-laxe-gustariame-ter-maisfillos-peliculasspan/0003_201909SF20P1992.htm

ANDERSON, Roger C. (1975). Reflections: Ecocinema: A Plan for Preserving Nature. BioScience, 25 (7).

BARREIRO GONZÁLEZ, María Soliña (2019). Filmar o dó. Dó de nós. Filmar a perda. En M. Ledo Andión (coord.). A foresta e as árbores. Para unha historia do cinema en lingua galega [2], pp. 2138. Vigo: Galaxia.

BRERETON, Pat (2005). Hollywood Utopia. Ecology in contemporary American cinema. Bristol: Intellect.

CASANOVA, Jorge (2019, 17 de mayo). Oliver Laxe: "O rural vive un holocausto". La Voz de Galicia. Recuperado de: https://www.lavozdegalicia.es/noticia/cultura/2019/05/16/oliver-laxe-ruralvive-holocausto/00031558021431873525454.htm 
CASTRO DE PAZ, José Luis (2020). Se fan sufrir é porque sofren. Réquiem pola Galiza Rural. en, M. Ledo Andión (coord.) De illas e sereas. Para unha historia do cinema en lingua galega [3]. Vigo: Galaxia.

CASTRO DE PAZ, José Luis (2019). Filmar as pulsións. Formas e montaxes do desexo. As pulsións e os seus destinos no cine en galego actual. En M. Ledo Andión (coord.). A foresta e as árbores. Para unha historia do cinema en lingua galega [2], pp. 139-177. Vigo: Galaxia.

COSTA, Jordi (2019, 11 de febrero). El bosque de los fuegos fatuos. El País. Recuperado de: https://elpais.com/cultura/2019/02/07/actualidad/1549562181_870663.html

FIANT, Antony (2014). Por un cinéma contemporain soustractif. Saint Denis: Press Universitaires de Vicennes.

GÓMEZ VIÑAS, Xan (2015). Do amateur ao militante implicacións políticas e estéticas do cinema en formato non profesional na Galiza dos anos 70. (Tesis doctoral). Santiago de Compostela: Servizo de Publicacións e Intercambio Científico-USC.

HAGEMAN, Andrew (2012). Ecocinema and Ideology: Do Ecocritics Dream of Clockwork Green?. En S. Rust, S. Monani \& S. Cubitt (eds.) Ecocinema. Theory and Practice. NY- London: Routledge, pp. 63-85.

HJORT, Mette. (2016). What Does It Mean to Be an Ecological Filmmaker?: Knut Erik Jensen's Work as Eco-Auteur. Projections. doi: 10. 10.3167/proj.2016.100206.

HJORT, Mette \& PETRIE, Duncan (eds.) (2007). The cinema of small nations. Edimburgo: Edinburgh University Press.

IGLESIAS, Eulália (2019, 8 de febrero). Trinta lumes: la poderosa fuerza del cine gallego. $E l$ Confidencial. Recuperado de: https://www.elconfidencial.com/cultura/cine/2019-02-08/trinta-lunesmisterio-galicia-critica-estrenos_1811222/

INGRAM, David (2012). The Aesthetics of Eco-film Criticism. En S. Rust, S. Monani \& S. Cubitt (eds.) Ecocinema. Theory and Practic, pp. 43-62. NY- London: Routledge.

KÄAPÄ, Pietari (2015). Ecology and contemporary Nordic cinemas. From Nation-building to Ecocosmopolitanism. London: Bloomsbury.

LEDO ANDIÓN, M. (coord.) (2020). De illas e sereas. Para unha historia do cinema en lingua galega [3]. Vigo: Galaxia.

LEDO ANDIÓN (coord.) (2019). A foresta e as árbores. Para unha historia do cinema en lingua galega [2]. Vigo: Galaxia.

LEDO ANDIÓN (coord.) (2019). Marcas na paisaxe. Para unha historia do cinema en lingua galega [1]. Vigo: Galaxia.

LU, Sheldon H. \& MI, Jiayan (eds). Chinese Ecocinema: In the Age of Environmental Challenge. Seattle: University of Washington Press.

MARTÍNEZ, Luis (2019, 7 de febrero). Trinta Lumes. La fascinación de lo invisible. El Mundo. Recuperado de: https://www.elmundo.es/metropoli/cine/2019/02/07/5c5af70d21 efa079228b46f3.html 
MARTÍNEZ, Beli (2015). O cine de non ficción no Novo Cinema Galego (2006-2012):

Conceptualización, contextos e singularidades. (Tesis doctoral). Vigo: Universidade de Vigo.

Recuperado de:

https://www.academia.edu/26089490/O_cine_de_non_ficci\%C3\%B3n_no_Novo_Cinema_Galego_20 06_2012_Conceptualizaci\%C3\%B3n_contextos_e_singularidades?auto=download\&email_work_card =download-paper

MARTÍNEZ, Beli (2015 b) Revisión de la etiqueta "Novo Cinema Galego". Testimonios de autor. En V. Fernández Guerra (Ed.), Revisitando el cine documental: de Flaherty al webdoc, Cuadernos Artesanos de Comunicación, 83, 127-152. La Laguna (Tenerife): Latina. Recuperado de: http://www.cuadernosartesanos.org/2015/cac83.pdf

MCDONALD, Scott (2004). Toward an Eco-cinema. Interdisciplinary Studies in Literature and the Environment, 11 ( 2 ), pp. 107 - 31. Recuperado de: https://academic.oup.com/isle/articleabstract/11/2/107/739174? redirectedFrom=PDF

MURRAY, Robin L.; HEUMANN, Joseph K. (2009). Ecology and popular. Cinema on the edge. Albany: State University of New York.

NOVOCINEMAGALEGO.INFO (s.f). O proxecto. Criterios. Recuperado de: http://novocinemagalego.info/o-proxecto/

PANSE, Silke (2013). Land as Protagonist-An Interview with James Benning. In A. Pick \& G. Narraway (eds). Screening Nature: Cinema Beyond the Human, pp. 60-72. New York - Oxford: Berghahn.

PÉREZ PEREIRO, Marta (2014). Paisaxe na néboa. Unha cartografía do cinema galego recente. Galicia 21, 77-91. Recuperado de: http://www.galicia21journal.org/F/pdf/Galicia21_F_06_Pereiro.pdf

PICK, Anat \& NARRAWAY, Guinevere (2013). Screening nature. Cinema beyond the human. NY: Berghahn.

REY, Ramón (2018, 2 de marzo). Entrevista a Diana Toucedo, directora de Trinta Lumes. Cine maldito. Recuperado de: https://www.cinemaldito.com/entrevista-a-diana-toucedo-directora-de-trintalumes/

REDONDO NEIRA, Fernando \& GONZÁLEZ RODRÍGUEZ, Xurxo (2015). Una propuesta de vertebracion del Novo Cine Galego: lo procesual y la marca documental. En V. Fernández Guerra (Ed.) Revisitando el cine documental: de Flaherty al webdoc, Cuadernos Artesanos de Comunicación, 83, 105-126 La Laguna (Tenerife): Latina. Recuperado de:

http://www.cuadernosartesanos.org/2015/cac83.pdf

ROCA BAAMONDE, Silvia; PÉREZ PEREIRO, Marta \& RODRÍGUEZ VÁZQUEZ, Ana Isabel (2016). Cines nacionales y lenguas no hegemónicas. La invisibilidad del gallego frente a las políticas de diversidad cultural. Cuadernos de Información y Comunicación, v. 21, Comunicación, cultura y diversidad, pp. 157-177. Recuperado de https://revistas.ucm.es/index.php/CIYC/article/view/52881

ROCA BAAMONDE, Silvia (2021). A representación do pobo galego a través da creación de personaxes de ficción da longametraxes cinematográficas. (Tesis doctoral). Santiago de Compostela: Universidade de Santiago de Compostela.

ROMERO SUÁREZ, Brais (2018, 13 de diciembre). Trote, de Xacio Baño. A cuarta parede. Recuperado de: www.acuartaparede.com/trote-de-xacio-bano/ 
RUST, Stephen, MONANI, Salma \& CUBITT, Sean (2012). Ecocinema. Theory and practice. NYLondon: Routledge.

SÁNCHEZ, Sergi (2019, 6 de febrero). Trinta lumes. Para los que cultivan el pensamiento mágico. Fotogramas. Recuperado de: https://www.fotogramas.es/peliculas-criticas/a26163880/trinta-lumescritica-pelicula/

YÁÑEZ, Manu (2018, 8 de agosto). Entrevista a Xacio Baño, que presenta "Trote" en el Festival de Locarno. Otros Cines Europa. Recuperado de: www.otroscineseuropa.com/entrevista-a-xacio-banoque-presenta-trote-en-el-festival-de-locarno/

\section{Original recebido em: 10 de junho de 2021}

Aceito para publicação em: 05 de julho de 2021

\section{Silvia Roca-Baamonde}

Doctora en Comunicación e Información Contemporánea por la Universidade de Santiago de Compostela (USC) e integrante del Grupo de Estudos Audiovisuais de la USC. Centra su investigación en el campo de los estudios culturales y la identidad, en el análisis de los estereotipos y discursos presentes en los medios — con especial atención a las representaciones nacionales y de género- - y en el estudio de los medios en lenguas no-hegemónicas y las pequeñas cinematografías.

\section{Marta Pérez-Pereiro}

Docente e investigadora en la Facultade de Ciencias da Comunicación de la Universidade de Santiago de Compostela (USC) e imparte clases en el área de Comunicación Audiovisual y Publicidad. Es integrante del Grupo de Estudos Audiovisuais de la USC. Coordina el Seminario Permanente de

Comunicación e Xénero - CO(M)XÉNERO. Sus principales temas de investigación son las pequeñas cinematografías, el humor en los medios y redes sociales y la rendición de cuentas en los medios.

\section{@ $\odot \otimes($}

Esta obra está licenciada com uma Licença

Creative Commons Atribuição-NãoComercial-CompartilhaIgual 4.0 Internacional 